\title{
BARRETT'S ESOPHAGUS: DOES AN ANTIREFLUX PROCEDURE REDUCE THE NEED FOR ENDOSCOPIC SURVEILLANCE?
}

Monica L. McDonald, MD

Victor F. Trastek, MD

Mark S. Allen, MD

Claude Deschamps, MD

Peter C. Pairolero, MD
Barrett's esophagus, a premalignant condition associated with chronic gastroesophageal reflux, carries an approximate 40 -fold increase in the incidence of adenocarcinoma. Between 1975 and 1994, 113 patients with Barrett's esophagus underwent antireflux procedures at the Mayo Clinic. The antireflux procedure was performed more than 3 months after the diagnosis of Barrett's disease in 39 patients $(34.5 \%)$ and during the initial preoperative evaluation in $74(65.5 \%)$. Uncut Collis-Nissen fundoplication was performed in 69 patients $(61.1 \%)$, Nissen fundoplication was performed in $16(14.2 \%)$, cut Collis-Nissen fundoplication was performed in 12 (10.6\%), Belsey repair was performed in nine $(\mathbf{8 . 0 \%})$, Collis-Belsey repair was performed in six $(5.3 \%)$, and Nissen fundoplication with an anterior gastropexy was performed in one $(0.9 \%)$. There was one operative death (0.9\% mortality). Morbidity occurred in 41 patients $(36.3 \%)$, including cardiac arrhythmia in eight $(\mathbf{7 . 0 \%})$, pneumonia in six $(5.3 \%)$, empyema in five $(4.4 \%)$, hemorrhage in four $(3.6 \%)$, myocardial infarction in two $(1.8 \%)$, and wound dehiscence, wound infection, perforated duodenal ulcer, and postoperative leak in one each $(0.9 \%)$. Median follow-up for the 112 survivors of operation was 6.5 years (range 4 months to 18.2 years). Excellent or good alleviation of symptoms was obtained in 92 patients $(82.2 \%)$. Ninety-nine patients $(88.4 \%)$ are currently alive and $13(11.6 \%)$ have died. Three patients $(2.7 \%)$ subsequently had adenocarcinoma of the esophagus after the antireflux procedure at 13, 25, and 39 months; two of these died of cancer. The incidence of esophageal carcinoma in this select group of patients was one in $\mathbf{2 7 3 . 8}$ patient-years of follow-up. We conclude that although antireflux procedures in patients with Barrett's esophagus result in long-term control of reflux symptoms, the possibility of esophageal cancer still exists. Endoscopic surveillance should therefore be recommended. (J Thorac Cardiovasc Surg 1996;111:1135-40)
$B^{3}$ arrett's esophagus (BE) is an acquired condition associated with excessive gastroesophageal reflux that occurs in approximately $15 \%$ of patients with reflux esophagitis. ${ }^{1}$ Patients with $\mathrm{BE}$ have a higher incidence of complications of reflux,

From the Section of General Thoracic Surgery, Mayo Clinic and Mayo Foundation, Rochester, Minn.

Read at the Twenty-first Annual Meeting of The Western Thoracic Surgical Association, Coeur d'Alene, Idaho, June 21-24, 1995.

Received for publication June 21, 1995; revisions requested Oct. 5, 1995; revisions received Jan. 6, 1996; accepted for publication Jan. 15, 1996.

Address for reprints: Victor F. Trastek, MD, 200 First St., S.W., Rochester, MN 55905.

Copyright (C) 1996 by Mosby-Year Book, Inc.

$0022-5223 / 96 \$ 5.00+0 \quad \mathbf{1 2 / 6 / 7 1 9 1 7}$ including stricture, ulceration, and the development of adenocarcinoma. ${ }^{2}$ The incidence of carcinoma associated with $\mathrm{BE}$ is unknown but has been estimated to range from one case per 16 to one per 441 patient-years. $^{3}$

$\mathrm{BE}$ is thought to arise from exposure of the esophageal mucosa to gastric or duodenal secretions. Consequently, elimination of gastroesophageal reflux should prevent complications. Antireflux operations have seldom been shown to lead to regression of the $\mathrm{BE},{ }^{4-9}$ however, and the influence of antireflux procedures (ARPs) on the development of carcinoma has not been well studied. ${ }^{10} \mathrm{We}$ retrospectively reviewed our experience with patients with BE who underwent ARPs to determine these procedures' effects on the development of esophageal adenocarcinoma. 
Table I. Indications for antireflux procedure in 113 patients with $B E$

\begin{tabular}{lcc}
\multicolumn{1}{c}{ Indications } & No. & $\%$ \\
\hline Refractory symptoms & 98 & 86.7 \\
Nondilatable stricture & 40 & 35.4 \\
Chronic anemia & 13 & 11.5 \\
Esophageal ulceration & 13 & 11.5 \\
Regurgitation with aspiration & 11 & 9.7 \\
Paraesophageal hernia & 11 & 9.7 \\
\hline
\end{tabular}

\section{Methods}

Between 1975 and 1994, 1935 patients with BE were evaluated at the Mayo Clinic. Of these, $113(5.8 \%)$ underwent ARPs. The diagnosis of BE in these 113 patients was confirmed by esophagogastroduodenoscopically directed biopsy, with four-quadrant biopsy samples obtained every $2 \mathrm{~cm}$. Our criteria for the diagnosis of $\mathrm{BE}$ have been previously published; we include patients with 3 $\mathrm{cm}$ or more of columnar epithelium or incomplete intestinal metaplasia with goblet cells (specialized columnar epithelium) in the esophagus, even if less than $3 \mathrm{~cm}$ in length. 11,12

We retrospectively analyzed each record for age, sex, symptoms, diagnostic evaluation, indications for operation, operative procedure, functional results, and development of esophageal carcinoma. Annual endoscopic surveillance was recommended after operation, and surveillance biopsy samples were reviewed for the development of dysplasia or carcinoma. After the ARP, functional results were considered excellent if the patient was eating a general diet without symptoms, good if symptoms were minimal and neither medication nor esophageal dilatation was required, fair if symptoms were improved but either medication or esophageal dilatation was required, and poor if symptoms were unchanged or worse. Patients were also questioned during follow-up for symptoms of reflux, dysphagia, diarrhea, or bloating. Operative mortality included those patients who died within the first 30 days or those who died later but during the same hospitalization. Freedom from esophageal adenocarcinoma was estimated by the Kaplan-Meier method, with the date of the ARP used as the starting point and the date of detection of the adenocarcinoma used as the endpoint. ${ }^{13}$

\section{Results}

There were 113 patients ( 78 men and 35 women) with BE who underwent ARPs. Median age at ARP was 68 years (range 11 to 92 years). Signs and symptoms were present before surgical intervention in 109 patients $(96.5 \%)$ and included heartburn in $77(68.1 \%)$, regurgitation in $59(52.2 \%)$, dysphagia in $56(49.6 \%)$, sternal pressure in $34(30.1 \%)$, aspiration in $30(26.5 \%)$, and hemorrhage in $15(13.3 \%)$. Associated esophageal diseases included scleroderma in four $(3.5 \%)$ and achalasia in one $(0.9 \%)$. Previous esophageal operations had been per- formed in 26 patients (23.0\%): previous ARP in 21 patients, esophagomyotomy in two patients, and tracheoesophageal fistula repair, Thal esophagogastric fundoplication for perforation, and repair of a Bochdalek hernia in one patient each.

All patients underwent esophagogastroduodenoscopy. In addition to diagnosing BE, the esophagogastroduodenoscopy demonstrated a diaphragmatic hernia in 85 patients $(75.2 \%)$, esophagitis in 68 $(60.2 \%)$, esophageal stricture in 41 (36.3\%), esophageal ulcer in $41(36.3 \%)$, mucosal nodularity and epiphrenic diverticulum in two $(1.8 \%)$ each, and hemorrhage in one $(0.9 \%)$. An upper gastrointestinal barium swallow test was performed in 98 patients $(86.7 \%)$ and demonstrated a sliding hiatal hernia in $86(87.8 \%)$, esophageal stenosis in 38 $(38.8 \%)$, and paraesophageal hiatal hernia in 14 (14.3\%). An esophageal motility test was performed in 81 patients and showed a reduced lower esophageal sphincter pressure in $48(59.3 \%)$, combined lower esophageal sphincter pressure and abnormal peristalsis in $12(14.8 \%)$, abnormal peristalsis only in six $(7.4 \%)$, achalasia in one $(1.2 \%)$, and obstruction with an inability to pass the catheter in one $(1.2 \%)$. Thirteen patients $(16.0 \%)$ had normal manometric findings. A 24-hour esophageal $\mathrm{pH}$ test was performed in 17 patients with positive results in 15 $(88.2 \%)$ and negative results in two $(11.8 \%)$. All patients were initially managed with a medical regimen consisting predominantly of histamine blockers and, more recently, omeprazole before consideration of ARP.

The most common indication for ARP (Table I) was the presence of symptoms that were refractory to medical therapy in 98 patients $(86.7 \%)$. Several types of ARP were performed during the duration of this study: uncut Collis-Nissen fundoplication in 69 patients $(61.1 \%)$, Nissen fundoplication in 16 $(14.2 \%)$, cut Collis-Nissen fundoplication in 12 $(10.6 \%)$, Belsey repair in nine $(8.0 \%)$, Collis-Belsey repair in six $(5.3 \%)$, and Nissen fundoplication plus anterior gastropexy in one $(0.9 \%)$. The ARP was performed at the initial diagnosis of $\mathrm{BE}$ in 74 cases $(65.5 \%)$ and more than 3 months after diagnosis in the remaining 39 (34.5\%). Fifteen patients (13.3\%) had other concomitant procedures performed during the ARP, including cholecystectomy in four cases, pulmonary wedge resection in three, vagotomy in three, antrectomy in two, and tracheotomy, planned splenectomy, and appendectomy in one case each.

There was one operative death ( $0.9 \%$ mortality). 
Cause of death was cardiac arrest. Intraoperative complications occurred in six patients $(5.3 \%)$ : splenectomy, gastrotomy, and esophageal perforation in two patients each $(1.8 \%)$. Postoperative complications occurred in 41 patients $(36.3 \%)$. Major complications included cardiac arrhythmia in eight $(7.0 \%)$, pneumonia in six $(5.3 \%)$, empyema in five $(4.4 \%)$, myocardial infarction in two $(1.8 \%)$, and wound dehiscence, wound infection, perforated duodenal ulcer, and esophageal leak in one patient each $(0.9 \%)$. Five patients $(4.4 \%)$ required early reoperation to control hemorrhage in two cases, to repair a wound dehiscence in one case, and to repair the previously mentioned perforated ulcer and esophageal leak in one case each. A postoperative water-soluble contrast esophageal swallow test was performed in 84 cases (74.3\%). Abnormal findings included obstruction in four patients and recurrence of a hernia in one. Six patients $(5.3 \%)$ required esophageal dilatation before discharge from the hospital. Median hospitalization was 9 days (range 4 to 83 ).

Follow-up was complete for all 112 survivors of operation, and ranged from 4 months to 18.2 years (median 6.5 years). At follow-up, functional results were rated as excellent in 77 patients $(68.8 \%)$, good in $15(13.4 \%)$, fair in $15(13.4 \%)$, and poor in 5 $(4.5 \%)$. Heartburn was present in 12 patients $(10.7 \%)$, dysphagia in $11(9.8 \%)$, bloating in seven $(6.3 \%)$, regurgitation in four $(3.6 \%)$, dumping in two $(1.8 \%)$, and early satiety in one $(0.9 \%)$. Four patients required postoperative dilatation after being discharged from the hospital.

Postoperative esophagogastroduodenoscopy was performed at least once in 72 patients $(64.3 \%)$. Data from the most recent esophagogastroduodenoscopic examination revealed perșistent $\mathrm{BE}$ in all patients. Additional abnormalities found in 28 patients included esophageal narrowing in 13 , esophagitis in 11, esophageal ulcer in 10, adenocarcinoma in two, high-grade dysplasia in one, esophageal diverticulum in one, and recurrent hiatal hernia in one. In the patients with postoperative evidence of esophagitis or ulcer, it could be concluded that there was less than full protection from gastroduodenal reflux. Thirty-nine patients $(34.8 \%)$ underwent an upper gastrointestinal barium swallow test after the ARP, which revealed esophageal stenosis in 10 , recurrence of the diaphragmatic hernia in nine, and gastroesophageal reflux in nine.

The two patients with adenocarcinoma and the one with high-grade dysplasia underwent esopha-

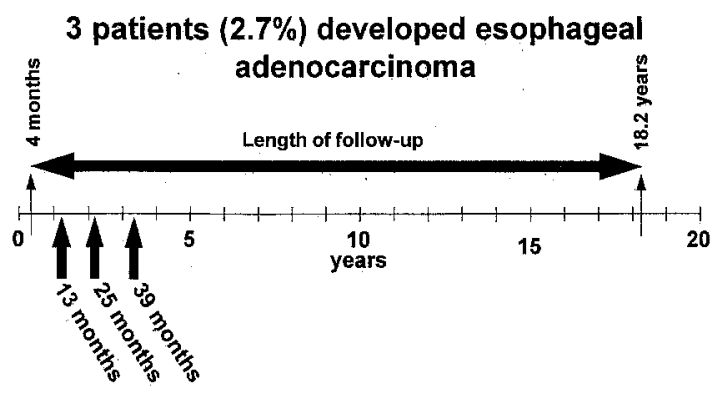

Fig. 1. Follow-up after ARP of 112 patients with BE. Arrows indicate time of diagnosis of adenocarcinoma after repair.

geal resection; the latter patient was found to have carcinoma in situ. All three of these patients were free of symptoms after ARP and were found to have specialized intestinal epithelium in esophageal biopsy samples after the ARP. Postsurgical stage was stage 0 (Tis N0 M0) in one patient, stage I (T1 N0 $\mathrm{M} 0$ ) in one, and stage IIB (T1 N1 M0) in one. There was one perioperative death after esophageal resection. Cause of death in this patient was rupture of the pulmonary artery during Swan-Ganz catheter placement. The second patient was alive and well 2 months after resection, but the third patient died of recurrent esophageal cancer at 15 months. Altogether, three patients $(2.7 \%)$ had adenocarcinoma of the distal esophagus during follow-up at 13, 25, and 39 months after the ARP. Of interest, no patients acquired carcinoma after 39 months, despite a median follow-up of 6.5 years and a maximum follow-up of 18.2 years (Fig. 1). The incidence of adenocarcinoma among the 112 survivors of operation was one per 273.8 patient-years of followup.

\section{Discussion}

$\mathrm{BE}$ represents a carcinogenic process from benign squamous epithelium to metaplastic columnar epithelium and dysplasia and ultimately to invasive adenocarcinoma. Why some patients are at risk for $\mathrm{BE}$ is uncertain, but the pathophysiology clearly appears to involve reflux of gastric and duodenal contents. ${ }^{14}$ Hopefully, further clarification of the pathophysiology will lead to ways to alter the process and prevent development of this complication and ultimately carcinoma.

Prevention of symptoms of reflux by eliminating reflux of gastric and duodenal contents can be successfully accomplished with an ARP. Do ARPs result in regression of $\mathrm{BE}$ and reduction in the risk 
of cancer, however? If so, when should patients undergo ARPs, and should mucosal ablation be added to ARPs? If not, how should these patients be followed up after ARPs?

Regression of BE after ARPs has not been proved. Although sporadic cases of regression have been reported, ${ }^{5-9}$ most studies, including this one, have failed to demonstrate regression after repair. ${ }^{15-19}$ These observations suggest that once $\mathrm{BE}$ becomes established, it is permanent.

Equally important as regression of $\mathrm{BE}$ is the continued risk of dysplasia and ultimately carcinoma after ARPs. Ideally, this risk would be eliminated after repair, but several studies have shown development of adenocarcinoma. ${ }^{20-23}$ Williamson and associates $^{23}$ noted that three of 37 patients $(8.1 \%)$ acquired carcinoma after ARPs. Similarly, Stein and associates ${ }^{20}$ reported on two patients who acquired adenocarcinoma at 50 and 106 months after ARPs, despite competent fundoplication as proved by manometric and $\mathrm{pH}$ monitoring. McCallum and colleagues $^{21}$ noted that only $3.4 \%$ of their patients demonstrated progression toward dysplasia after ARPs, compared with $19.7 \%$ of those followed up after medical treatment. In our series of 112 survivors of operation, three acquired adenocarcinoma during follow-up, an incidence of one case per 273.8 patient-years of observation. Of interest, all three of our patients acquired adenocarcinoma in the early follow-up period (less than 3.3 years), despite the fact that median follow-up was 6.5 years and extended to 18.2 years. Where are the late cancers? Were these three adenocarcinomas occult at the time of the ARP and simply not detected? If this was indeed the situation, and no new cancers developed during late follow-up, these observations suggest possibly that progression did not occur after an ARP.

Because the risk of adenocarcinoma associated with $\mathrm{BE}$ continues to be present after an $\mathrm{ARP}$, we currently recommend surveillance in these patients. Our practice is to obtain annual four-quadrant biopsy samples every $2 \mathrm{~cm}$ of the remaining $\mathrm{BE}$. We hope that future advances, such as endoscopic ultrasonography and molecular markers, may provide a method to identify mucosa at risk for transformation into invasive carcinoma. It is also important to stress the need for follow-up objective reflux testing, which should include motility and 24-hour $\mathrm{pH}$ studies, in these patients. Presence of reflux would suggest an incompetent ARP, and any protective effect would most likely be negated.

If one accepts the pathophysiology of $\mathrm{BE}$, when should one intervene with an ARP? Current medical therapy reduces only the acid component of reflux. In contrast, a successful ARP can prevent reflux of both acid and duodenal contents. Recommendations for ARPs in patients with BE, however, have been similar to those for patients who have gastroesophageal reflux problems without BE. Should patients with BE undergo an ARP at diagnosis of BE, irrespective of symptoms? Although no convincing evidence exists to suggest that $\mathrm{BE}$ will regress or that the development of carcinoma will be eliminated, our study surprisingly failed to demonstrate the development of adenocarcinoma in the late phase of follow-up. In addition, McCallum and associates $^{21}$ noted that the incidence of dysplasia was less after an ARP than after medical treatment. These observations, if confirmed, would suggest that ARPs may be successful in preventing the development of new cancers.

The benefits of early surgical intervention must be defined and weighed against the risk. In our review, risks were not insignificant and included an operative mortality rate of $0.9 \%$ and a postoperative complication rate of $36.3 \%$. Nearly one fourth of our patients had undergone previous esophageal operations, however, which undoubtedly increased risks of the current operation. Despite this, we are giving much stronger consideration to ARPs at diagnosis of BE than we had previously. Perhaps in the future the role of the laparoscopic ARP, if it withstands the test of time, will be better defined. Also, if ablation of Barrett's mucosa after an ARP can be done successfully, this may be the most complete method of preventing the development of cancer. $^{24}$

In conclusion, patients with $\mathrm{BE}$ undergoing ARPs for reflux receive good long-term control of symptoms. Despite this, the Barrett's mucosa and the ability for esophageal cancer to develop still exists. For this reason, we continue to recommend endoscopic surveillance after repair.

\section{REFERENCES}

1. Winters C Jr, Spurling TJ, Chobanian SJ, Curtis DJ, Esposito RL, Hacker JF 3rd, et al. Barrett's esophagus: a prevalent, occult complication of gastroesophageal reflux disease. Gastroenterology 1987;92:118-24.

2. Cameron AJ, Ott J, Payne WS. The incidence of adenocarcinoma in columnar-lined (Barrett's) esophagus. N Engl J Med 1985;313:857-9.

3. Streitz JM Jr, Ellis FH Jr. Barrett's esophagus. In: Shields TW, ed. General thoracic surgery, vol 2. 4th ed. Baltimore: Williams \& Wilkins, 1994:1612-21.

4. Williamșon WA, Ellis FH Jr, Gibb SP, Shahian DM, Aretz 
HT. Effect of antireflux operation on Barrett's mucosa. Ann Thorac Surg 1990;49:537-42.

5. Skinner DB, Walther BC, Riddell RH, Schmidt H, Iascone C, DeMeester TR. Barrett's esophagus: comparison of benign and malignant cases. Ann Surg 1983;198:554-65.

6. Harle IA, Finley RJ, Belsheim M, Bondy DC, Booth M, Lloyd D, et al. Management of adenocarcinoma in a columnar-lined esophagus. Ann Thorac Surg 1985;40:330-6.

7. Radigan LR, Glover JL, Shipley FE, Shoemaker RE. Barrett's esophagus. Arch Surg 1977;112:486-91.

8. Ransom JM, Patel GK, Clift SA, Womble NE, Read RC. Extended and limited types of Barrett's esophagus in the adult. Ann Thorac Surg 1982;33:19-27.

9. Brand DL, Ylvisaker JT, Gelfanc M, Pope CE 2nd. Regression of columnar esophageal (Barrett's) epithelium after antireflux surgery. N Engl J Med 1980;302:844-8.

10. Attwood SE, Barlow AP, Norris TL, Watson A. Barrett's oesophagus: effect of antireflux surgery on symptom control and development of complications. Br J Surg 1992;79:1050-3.

11. Pera M, Trastek VF, Carpenter HA, Allen MS, Deschamps C, Pairolero PC. Barrett's esophagus with high-grade dysplasia: an indication for esophagectomy? Ann Thorac Surg 1992;54:199-204.

12. Pera M, Trastek VF. Barrett's esophagus. In: Little AG, ed. Chest surgery clinics of North America: benign esophageal disease. Philadelphia: Saunders, 1994:705-19.

13. Kaplan EL, Meier P. Nonparametric estimation from incomplete observation. J Am Stat Assoc 1958;53:457-81.

14. Pera M, Trastek VF, Pairolero PC, Cardesa A, Allen MS, Deschamps C. Barrett's disease: pathophysiology of metaplasia and adenocarcinoma. Ann Thorac Surg 1993;56:1191-7.

15. Endo M, Kobayashi S, Kozu T, Takemoto T, Nayakama K. A case of Barrett epithelialization followed up for five years. Endoscopy 1974;6:48-51.

16. Naef AP, Savary M, Ozello L. Columnar-lined lower esophagus: an acquired lesion with malignant predisposition: report on 140 cases of Barrett's esophagus with 12 adenocarcinomas. J Thorac Cardiovasc Surg 1975;70:826-35.

17. Starnes VA, Adkins RB, Ballinger JF, Sawyers JL. Barrett's esophagus: a surgical entity. Arch Surg 1984;119:563-7.

18. Dooner J, Cleator IG. Selective management of benign esophageal strictures. Am J Gastroenterol 1982;77:172-7.

19. Mangla JC, Schenk EA, Desbaillets L, Guarasci G, Kubasik NP, Turner MD. Pepsin secretion, epsinogen and gastrin in "Barrett's esophagus": clinical and morphological characteristics. Gastroenterology 1976;70:69-76.

20. Stein HJ, Siewert JR, Holscher AH, et al. Nissen fundoplication in Barrett's esophagus. Presented at: Thirty-fifth Annual Meeting of the Society of Surgery of the Alimentary Tract. New Orleans: Society of Surgery of the Alimentary Tract, 1994.

21. McCallum RW, Polepalle S, Davenport K, Frierson H, Boyd S. Role of antireflux surgery against dysplasia in Barrett's esophagus. Gastroenterology 1991;100:A121.

22. Pearson FG, Cooper JD, Patterson GA, Prakash D. Peptic ulcer in acquired columnar-lined esophagus: results of surgical treatment. Ann Thorac Surg 1987;43:241-4.

23. Williamson WA, Ellis FH Jr, Gibb SP, Shahian M, Aretz HT. Effect of antireflux operation on Barrett's mucosa. Ann Thorac Surg 1990;49:537-42.

24. Wang KK. Barrett's esophagus: current and future management. Compr Ther 1994;20:36-43.

\section{Discussion}

Dr. Alex G. Little (Las Vegas, Nev.). Fịrst, I congratulate the program committee for starting the program with a presentation on the esophagus. I think an important point has been made, with all apologies to our president, that the esophagus is the most important muscular pump in the chest.

I also congratulate Dr. McDonald on an excellent presentation and congratulate her and her colleagues for making an important point about the relationships among $\mathrm{BE}$, reflux, surgical control of reflux, and carcinoma. They have shown that patients continue to be at risk for development of adenocarcinoma after surgical control of reflux. The literature contains anecdotal reports that suggest the same conclusion, but to my knowledge this is the first time it has been based on a prospectively followed large group of patients who were operated on for symptomatic reflux, had $\mathrm{BE}$, and were shown to acquire carcinoma afterward. So the important point, which certainly should be recognized by surgeons and also I hope transmitted to gastroenterologists, is that patients need to be followed up after operation.

I do have a few questions. I think that the presentation and the manuscript actually stop a little short of addressing a few other issues that have been raised and could be answered.

The first has to do with the definition of BE. Barrett described patients who had an ulcer in the midesophagus followed by $10 \mathrm{~cm}$ or more of columnar epithelium in the esophagus. You included patients with any amount of columnar epithelium in the esophagus. I suggest that this is a broader criterion than most physicians would use, and it increases the denominator in your risk-factor analysis considerably. Would you please comment on that?

Dr. McDonald. We state in the Methods section that now we include if less than $3 \mathrm{~cm}$ if goblet cells are found on biopsy.

Dr. Little. I accept that, and I think the important thing is that you are very clear about it, but $I$ think that it is a broader definition than many physicians would use.

Second, for your three patients with carcinoma, I wonder whether you actually have proof, either clinically or ideally with some direct measurements, that you did successfully curtail reflux in those patients.

Dr. McDonald. Clinically, all three patients were free of symptoms after the ARP. On endoscopy, two patients had normal results and one had esophagitis. We did not do 24-hour $\mathrm{pH}$ monitoring of those patients.

Dr. Little. That is always the caveat that comes upmaybe those patients did not really get control of their reflux. I am seriously prepared to accept that they did, but it is an important point.

Also, all patients who went on to acquire carcinoma had specialized intestinal epithelium, and it is a common observation that essentially all patients with $\mathrm{BE}$ who get adenocarcinoma have this particular variant. Should such patients be treated more aggressively? Should they undergo resection?

Dr. McDonald. That is among the future issues that need to be addressed, whether patients with specialized intestinal epithelium or patients with ulcers or strictures who are at higher risk should be treated more aggres- 
sively. The answer to this question really is up in the air right now. What role laparoscopic Nissen mucosal ablation will have in future management remains to be seen.

Dr. Little. The final question that obviously begs to be asked is what you think the role is for ARP in patients with BE. Is it only for control of symptoms, which I believe is a conclusion to be read into your article and one with which I agree, or would you suggest that there is a role for so-called prophylactic antireflux operations to prevent the development of adenocarcinoma?

Dr. McDonald. I think that the ARP can halt the progression from Barrett's metaplasia to dysplasia to carcinoma. As you noticed from our study, the three patients who did acquire cancer all did so very early, which leads to the question of whether these were just early catcinomas missed at the time of ARP.

Dr. Little. I will conclude by saying that I think to some extent you are trying to have it both ways. Patients with $\mathrm{BE}$ need to be monitored for the risk of cancer, yet this operation can prevent the development of cancer. It ought to be one way or the other.

Dr. Arthur N. Thomas (San Francisco, Calif.). I enjoyed your paper very much, and this is an issue that I think all of us are seeing with increasing prominence. In my own practice, the prevalence of adenocarcinoma of the esophagus, particularly in the gastroesophageal junction region, has grown to maybe $60 \%$ to $80 \%$ of the people on whom we perform esophagectomy. I have a distinct impression that your group is atypical, for two reasons. One is that the patients with BE classically do not have a strong history of antireflux, and yours were intercepted quite quickly. Second, many of the medically treated patients were treated this way for a relatively brief time. The patients I see with $\mathrm{BE}$ that undergoes malignant degeneration or evidences atypical mucosa have been treated with histamine blockers or omeprazole for a number of years, and I would like you to comment on whether you think that prolonged medical therapy is related to this increased incidence of carcinoma involving $\mathrm{BE}$.

Dr. McDonald. You are right, most of our patients who were treated medically were not treated this way for a long period. Previous studies have shown that medications by themselves do not halt the progression to carcinoma, so something further than just medical therapy needs to be done.

Dr. Thomas. Do you have any impressions regarding the efficacy of surveillance by gastroenterologists in terms of detecting early carcinoma?

Dr. McDonald. That all depends on your endoscopists and the number of biopsies you perform. If you have a good pathologist and you do four-quadrant biopsies every $2 \mathrm{~cm}$, you can be more accurate than people who are not doing as thorough an endoscopic procedure.

Dr. Thomas. The final question I would ask you is what you would consider premalignant; if it were yourself, would you want an ARP or would you want to have the Barrett's epithelium removed in some more extensive procedure?

Dr. McDonald. Anyone who has high-grade dysplasia should have the esophagus removed; for patients with low-grade dysplasia, we recommend medical management and biopsy every 3 months.
Dr. Tom R. DeMeester (Los Angeles, Calif.). I compliment Dr. McDonald on the quality of her presentation. Adenocarcinoma of the esophagus is the fastest rising cancer in the western world, having tripled in incidence since the 1970s. This presentation focuses on that issue. The only data available regarding the protective benefits of ARP were published by McCallum and associates. ${ }^{21}$ They reported on a registry of patients with $\mathrm{BE}$ who were free of dysplasia. Some were treated medically and others were treated surgically; they were followed up for about 5 years. They showed that the incidence of dysplasia or cancer developing was less in the surgical population. The study has been criticized because of the entrance criteria. For example, how extensively were these patients' tissues sampled for biopsy before entry to be sure that they were free of dysplasia? Consequently, this presentation could have a profound impact on the treatment of patients with BE. For this reason, I ask the following questions:

First, it is important to be precise regarding the effectiveness of the repair in patients with $\mathrm{BE}$ who acquire cancer. If the message is that ARP does not protect against the development of cancer, the impact will be to limit the use of surgical therapy, even though it is the most effective antireflux therapy. The report that some patients had esophagitis suggests that the repair may not have been competent and that reflux continued, resulting in repetitive injury and progression of the $\mathrm{BE}$ to dysplasia and cancer. Our experience indicates that it is uncommon for us to operate on a patient with Barrett's adenocarcinoma who has had a previous competent ARP. I can count them on one hand. Yet we have operated on scores of patients with Barrett's adenocarcinoma who have been receiving long-term medical treatment:

An important question is how many biopsy samples you require to exclude an early cancer before proceeding with ARP in someone with BE. How do you exclude the error of doing an ARP in the presence of an early carcinoma?

Dr. McDonald. What we currently recommend is fourquadrant biopsy samples every $2 \mathrm{~cm}$, and you also sample any suspicious area extensively.

Dr. DeMeester. Did all of these patients undergo biopsy in that manner?

Dr. McDonald. Yes, they did.

Dr. DeMeester: BE can be end-stage reflux disease associated with decreased esophageal body contractility and a shortened esophagus from scarring. You seem to have taken the latter into consideration by doing a Collis gastroplasty, but I am concerned about doing a full fundoplication in a patient who may have poor propulsion. I noticed that your dysphagia rate was about $11 \%$ and that your fair and poor results were around $20 \%$. Do you think those results would improve if you did a partial fundoplication?

Dr. McDonald. I do not know for sure whether we could have improved them. Currently, we obtain motility studies, and if there is some evidence of dysfunction we alter our operation. The favored operation at Mayo in the past has been the uncut Collis-Nissen fundoplication, but we alter that operation if patients have abnormal peristalsis.

Dr. DeMeester. So at present your philosophy is to alter the degree of fundoplication if there is a reduction in contraction amplitude?

Dr. McDonald. Yes, it is. 